\section{Computing: The 1940s and 1950s}

\section{Robin Wilson and Martin Campbell-Kelly}

$T$ he modern computer age began in the Second World War, with Colossus in England, used for deciphering German military codes, and ENIAC in the United States. In 1932, led by Marian Rejewski, Polish codebreakers had managed to break the codes used by the Germans in their Enigma machines.

With the outbreak of the Second World War, the Enigma codes became much more complex, and many lives were
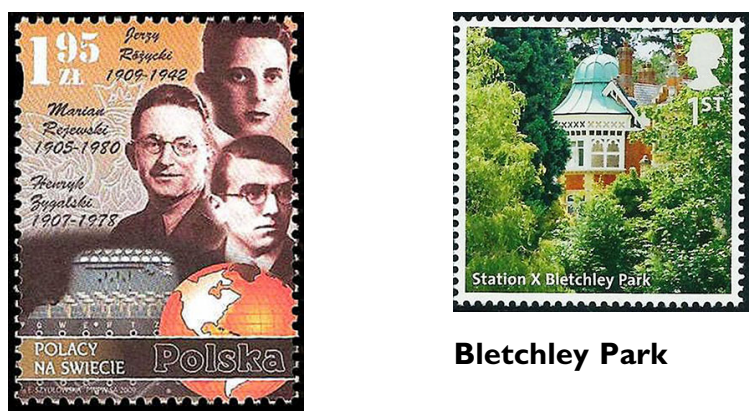

Bletchley Park

Polish codebreakers
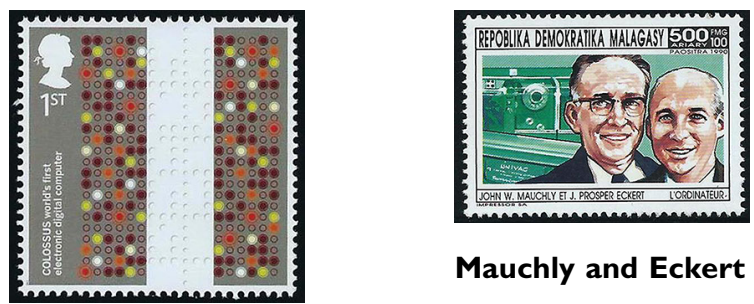

Mauchly and Eckert lost through the inability to break them. It was some time before a team of codebreakers at Bletchley Park, in England, led by Alan Turing, managed to do so with the aid of the Bombe machine.

The more secure Lorenz cipher machine was used by Hitler and other German war leaders to send their messages. To break this code, the first Colossus computer was developed in great secrecy at Bletchley Park. The achievements of Turing and his fellow codebreakers may have helped to shorten the war by two years.

Meanwhile, in the United States, John Mauchly and J. Eckert, professors at the Moore School of Electrical Engineering at the University of Pennsylvania, designed the first general-purpose electronic digital computer, the ENIAC (Electronic Numerical Integrator And Computer). The ENIAC was large and cumbersome: it weighed 30 tons; contained 17,000 vacuum tubes, 70,000 resistors, 10,000 capacitors, 1500 relays, and 6000 switches; and consumed $150 \mathrm{~kW}$ of electric power. The Hungarian-born mathematician John von Neumann worked with the ENIAC team to design its successor, the EDVAC, on which almost all subsequent computers have been based.

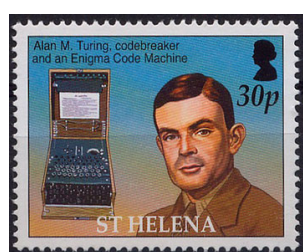

Alan Turing

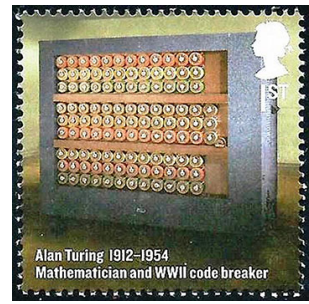

Turing's Bombe

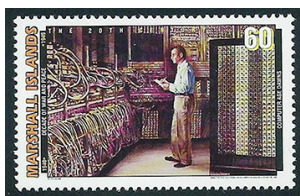

ENIAC

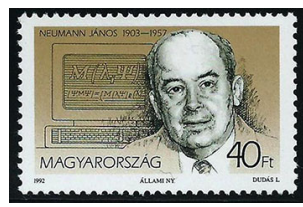

John von Neumann

\title{
Colossus
}

> Column editor's address: Robin Wilson, Mathematical Institute,

Andrew Wiles Building, University of Oxford, UK

e-mail: r.j.wilson@open.ac.uk

Martin Campbell-Kelly

Department of Computer Science

University of Warwick

Coventry CV4 7AL, UK

e-mail: m.campbellkelly@gmail.com
Publisher's Note Springer Nature remains neutral with regard to jurisdictional claims in published maps and institutional affiliations. 